\title{
Bultmann se ontmitologiseringsprogram
}

\section{herwaardeer}

\author{
Gert Malan ${ }^{1}$ \\ Navorser: Departement Nuwe-Testamentiese Wetenskap \\ Universiteit van Pretoria
}

\begin{abstract}
Bultmann's demythologising program reevaluated

The kerygma of the New Testament is depicted in the mythological language of a bygone mythological world-view. Bultmann suggested that demythologisation is necessary in order to explore the true Existenzverständniss contained in the mythological concepts. Reaction to his program of demythologising was mostly negative, especially in South Africa. This article focuses on the necessity for demythologisation as well as Bultmann's definition of myth, in order to reevaluate his program of demythologisation. Bultmann's demythologising program is considered as a responsible method for interpreting the texts of the New Testament.
\end{abstract}

\section{INLEIDING}

Om op Bultmann se tekortkominge te wys was die tydverdryf van 'n hele geslag geleerdes in ons land (Loubser 1996:49). Met hierdie stelling kan daar tot 'n groot mate saamgestem word. Daar is in Suid-Afrika maar enkele teoloë wat met waardering kennis geneem het van Bultmann se fenomenale teologiese nalatenskap en spesifiek van sy ontmitologiseringsprogram. Die rede daarvoor is dat Bultmann deur baie beskou is as ketter en ondergrawer van die Christelike geloof vanweě sy insigte en uitsprake wat die tradisionele denkmodelle waarin teologie beoefen is, bevraagteken het. Vanuit hierdie konteks het baie hom misverstaan en het vele hom op grond van hoorsê tot ketter verklaar sonder om self die moeite te doen om te lees wat hy te sê gehad het (Pelser 1987:162-

\footnotetext{
I Dr Gert J Malan is as navorsingsassosiaat betrokke by prof dr Andries $\mathrm{G}$ van Aarde se navorsingsprojek “Bybelse teologie en hermeneutiek", Departement Nuwe-Testamentiese Wetenskap, Fakulteit Teologie, Universiteit van Pretoria
} 
163). Ek is van mening dat dit veral met betrekking tot sy ontmitologiseringsprogram waar is.

Een van die redes hiervoor is myns insiens die ongelukkige woordkeuse om sy hermeneutiese model die benaming ontmitologisering te gee. Alhoewel Bultmann met die benaming sy eiesoortige benadering bedoel het, meen ek dat die gevaar van misverstaan onmiddellik inherent was aan die benaming. Die samestelling van die woord as sulks dra daartoe by. Die voorvoegsel dui aan dat iets weggeneem of uitgehaal word en die woordstam dui die mite as die objek aan. Daarom is dit verstaanbaar dat die gevolgtrekking vanuit die benaming gemaak kan word dat Bultmann se program ten doel gehad het om die mitologiese uit die Nuwe Testament te elimineer, terwyl hy juis nie so te werk gegaan het nie. Wie werklik die gees en inhoud van sy ontmitologiseringsprogram wil verstaan, sal sy werke daaroor moet lees.

Die toepassing van sy ontmitologiseringsprogram op 'n Nuwe-Testamentiese teks (2 Pet 3:1-18) en 'n vergelyking van diè resultate met dié van die kennissosiologie, werp 'n positiewe lig op sy program (vgl Malan \& Van Aarde 1998:529-543). Die feit dat die resultate mekaar nie weerspreek nie, maar grotendeels ondersteun en aanvul, is bewys daarvan dat Bultmann se benadering 'n grondige en eerlike poging is om die mitologiese spreekwyse van die Nuwe-Testamentiese tekste vir moderne mense verstaanbaar te maak. Die toepassing van sy ontmitologiseringsprogram op die genoemde teks het juis nie die apokaliptiese eskatologie van die teks geëlimineer nie maar dit eksistensiaal geïnterpreteer sodat die outeur se idee van outentieke bestaan in terme van die regverdigheid van God bèlig kon word. Die resultate dui aan dat ons met die ontmitologiseringsprogram 'n bruikbare en verantwoorde hermeneutiese instrument het waarmee die mitologiese taal van die Nuwe-Testamentiese tekste vir prediking en teologie in die moderne wêreld ontsluit kan word.

\section{OOR DIE NOODSAAKLIKHEID VAN ONTMITOLOGISE- RING}

Om van moderne mense te verwag om die mitologiese wêreldbeeld as die waarheid te aanvaar, is volgens Bultmann (1967:16-17) beide sinloos en onmoontlik. Dit is sinloos omdat hierdie wêreldbeeld nie spesifiek Christelik is nie, maar die wêreldbeeld van 'n 
vergange tyd is waarop die wetenskaplike denke nog nie ' $n$ invloed uitgeoefen het nie. Dit is onmoontlik vir moderne mense om hierdie vergange wêreldbeeld te aanvaar, omdat 'n mens nie ' $n$ wêreldbeeld bloot aanvaar deur ' $n$ besluit te neem nie. 'n Wêreldbeeld is 'n gegewenheid saam met 'n bepaalde historiese situasie. Hoewel 'n wêreldbeeld kan verander, en die individu selfs kan help om so 'n verandering te bewerkstellig, is so 'n verandering die gevolg van sekere feite wat onomwonde bewys dat die bestaande wêreldbeeld ontoereikend is. Om dus te dink dat 'n mitologiese wêreldbeeld deur 'n blote wilsbesluit aanvaar kan word, hou nie met hierdie realiteit rekening nie. Die NuweTestamentiese wêreldbeeld kan inderdaad as ' $n$ probleem vir moderne mense se verstaan van die Nuwe-Testamentiese kerugma beskryf word.

Die Nuwe-Testamentiese wêreldbeeld is ' $n$ mitologiese een waarvan individuele motiewe teruggevoer kan word na kontemporêre mitologie van die Joodse apokaliptiek en die gnostiese verlossingsmite (Bultmann 1960:82). In soverre dit alles mitologiese taal is, is dit volgens Bultmann vir die moderne mense ongeloofwaardig omdat die mitologiese wêreldbeeld vir hulle iets van die verlede is. Daarom word die Christelike verkondiging voor die vraag gestel of daar van die moderne mens van wie geloof verwag word, ook verwag word dat hulle die mitologiese wêreldbeeld moet erken. Indien dit 'n onmoontlike verwagting sou wees, moet die kerk die vraag beantwoord of die NuweTestamentiese verkondiging 'n waarheid bevat wat onafhanklik van die mitologiese wêreldbeeld staan. Indien wel, is dit die taak van die kerk om die Christelike verkondiging te ontmitologiseer (Bultmann 1967:16).

Twee ander argumente word deur Bultmann aangevoer om die noodsaaklikheid van ontmitologisering aan te dui. Die aard van mites, naamlik om nie in die eerste plek 'n objektiewe wêreldbeeld weer te gee nie, maar om iets te sê oor hoe mense hulleself in die wêreld verstaan, vereis eksistensiale interpretasie (Bultmann 1967:22). Anders as met blote kosmologiese interpretasie, kom eksistensiale interpretasie neer op 'n ontmitologiserende soeke na die uitdrukking van menslike eksistensie wat in mites gelee is. Daarby vereis die Nuwe Testament self ontmitologisering omdat daarin uitsprake vervat is wat disharmonieus en selfs direk weersprekend is van ander uitsprake daarin (Bultmann 1967:23). 
Een van Bultmann (1960:89; 1967:23) se belangrikste argumente ten gunste van ontmitologisering is sy stelling dat die Nuwe Testament self reeds hier en daar begin ontmitologiseer het.

Myns insiens is een van die belangrikste winspunte van Bultmann se ontmitologiseringsprogram sy vertrekpunt, naamlik dat ontmitologisering noodsaaklik is. Sy herhaalde beklemtoning daarvan dat die Nuwe-Testamentiese wêreldbeeld mitologies is, en daarom nie deur moderne Westerlinge gehandhaaf kan word nie, is volgens my ' $\mathrm{n}$ basiese hermeneutiese vooronderstelling vir die verantwoordelike omgang met die tekste van die Nuwe Testament. Daarmee ontken ek nie die moontlikheid dat sommige moderne mense soms in mitologiese begrippe dink of praat nie. Die probleem lê vir my by die verstaanbaarheid van die Nuwe-Testamentiese mitologiese taal in die moderne wêreld. Norman Perrin (1979:84) stel die saak in perspektief: Die moderne mense se wêreldbeskouing het soveel sedert die Nuwe-Testamentiese tydvak verander. Vandag beskou die moderne mense die aarde as ' $n$ obskure planeetjie in ons sonnestelsel wat maar een van biljoene sonnestelsels is. Oor die presiese tydstip en manier van totstandkoming daarvan is daar uiteenlopende menings, maar weinig bewyse. Die mens word deur die natuurwetenskap as 'n relatiewe laatkommer op aarde bestempel, met 'n totale historiese bestaan van ongeveer tienduisend jaar. Vergeleke met die ouderdom van die aarde is dit onbenullig en vergeleke met die ouderdom van die heelal, skyn die heelal tydloos te wees. Wat die historiese verloop van die mensdom betref, is die beskouing van vele mense, dat indien die mense nie self op 'n verwoestende wyse 'n einde aan hulle bestaan op aarde maak nie, sal die aarde in ieder geval met tyd geleidelik die vermoë verloor om menslike lewe in stand te hou. Met hierdie soort wêreldbeskouing is dit vir moderne mense moeilik om aan die mens te dink as 'n wese wat in die geskiedenis gekonfronteer word deur 'n Mag wat vir die totstandkoming van die heelal en lewe verantwoordelik was (Perrin 1979:84). Dit is juis hier waar die krag van Bultmann se ontmitologiseringsprogram lê. Ek meen dat Bultmann, sonder om aan die skandalon van die kruis van Christus afbreuk te doen, daarin geslaag het om die Nuwe-Testamentiese kerugma so te interpreteer dat ook die moderne mens met die intensie van die kerugma van die Nuwe Testament gekonfronteer word. 
Vir Bultmann (1967:23) was die noodsaaklikheid van ontmitologisering 'n vanselfsprekende saak wat reeds in die Nuwe Testament ' $n$ aanvang geneem het. Ulrich Luz (1966:367) was dit met hom eens: So ist es richtig, zu sagen, daß das Neue Testament selbst die Aufgabe der Entmythologisierung stellt. Ook vir sy standpunt dat die wetenskaplike wêreldbeeld ontmitologisering vereis (Bultmann 1967:16-21), was daar ondersteuning. So het Schelkle erken dat ons moderne mense moeite ondervind in ons omgang met mites. Darum bleiben Entmythologisierung unsere Aufgabe (Schelkle 1985:265). Vir Bultmann was ontmitologisering 'n eerlike poging om die NuweTestamentiese kerugma wat in mitologiese taal en wêreldbeeld geklee was, vir die moderne mens verstaanbaar en relevant te hou.

Vir sommige van sy kritici was die noodsaaklikheid van ontmitologisering nie so voor die hand liggend nie. Volgens Hans Jonas (1982:6-7) was dit ondenkbaar waarom Bultmann gemeen het dat dit noodsaaklik of selfs enigsins moontlik was om die mitologiese taal van die Nuwe Testament vir die moderne mense verstaanbaar te vertaal deur middel van ontmitologisering. Interpretasie is volgens Jonas (1982:7) slegs moontlik wanneer dit geskied van een metafoor na ' $\mathrm{n}$ ander metafoor: "... from outworn to no longer viable to fresh and newly appealing metaphor." Oor die Jenseits kan daar volgens Jonas slegs op ' $\mathrm{n}$ indirekte wyse gepraat word, andersins glad nie, daarom is die metaforiese taal van die mite onontbeerlik en is ontmitologisering onwenslik.

Klaus Bockmuehl (1988:18) meen dat die moderne en tegnologiese wêreldbeeld nie noodwendig ontmitologisering noodsaak nie en verwys in hierdie verband na die werke van wetenskaplikes soos A Loen en C F von Weizsäcker wat ook vanuit die moderne wêreldbeeld geredeneer het, maar by totaal ander gevolgtrekkings as Bultmann gekom het. Bultmann se ontmitologiseringsprogram is selfs vanuit die sogenaamde supernaturalistiese benadering, met 'n kennissosiologiese bril op, bestempel as 'n poging om die moderne wetenskaplike wêreldbeeld te legitimeer (so De Silva 1992:7).

Ander teoloě was dit weer met hom eens dat onmitologisering noodsaaklik was, maar het met hom oor die metode daarvan verskil (vgl Grässer 1994:277). Uit SuidAfrikaanse bodem meen Schoeman (1981:10-22) dat Christus aan die kerk die taak van ontmitologisering opgelê het ten opsigte van die Skrif en leefwêreld. Dit is 'n taak wat volgens Schoeman ondanks Bultmann se ontmitologiseringsprogram met alle erns 'n 
aanvang moet neem. Vir hom is die basiese boodskap van die Bybel nie wesenlik mities nie. Die mites, mitiese temas en mitiese elemente is egter die erdekruike waarin ons die skat ontvang het en in vele gevalle steeds die enigste wyse waarop ons die skat kan dra en koester. Enige ontmitologisering wat daarop gerig is om die transendentale vate waarin God sy genadige openbaring gegiet het, te verbrysel en sodoende die mense en hulle wêreld te humaniseer, is ongenadig en hou die gevaar in dat ons die hele diepte van God se wysheid kan verloor (Schoeman 1981:18). Dit het vir hom die moontlikheid dat mense tot 'n uitsiglose tyd en bestaan van hier en nou verdoem word asook dat mense selfs van die hede vervreem kan word omdat hulle van die ewigheid vervreem word. Daarmee bevraagteken hy Bultmann se program van ontmitologisering. Anders as Bultmann is hy cortuig daarvan dat die beginsel van die mite ook by die moderne mens voorkom en dat dit raakgesien sal word sodra die begrip mite van primitiewe en pejoratiewe assosiasies bevry word. Vir hom is die vraag of dit nie 'n halwe waarheid is wanneer daar van die premisse vertrek word dat die moderne mens nie meer dink in die argaïese en mitiese van die vroeëre denkwêreld nie. Hy erken dat die probleem rondom die mite is dat die mens nie daardeur tot die regte verstaan van die werklikheid en in die regte verhouding met die werklikheid bring nie, alhoewel dit voorgee om dit wel te doen. Sy oplossing is dat alles wat aan die volle Waarheid afbreuk wil doen, daarvan wil weglei of verlei, aan die kaak gestel moet word, sodat die ewige Christus en sy boodskap ons tot die regte verstaan en verhouding met die werklikheid kan bring. Hy noem sy benadering sosiale ontmitologisering wat, anders as die teologiese weergawe, vanuit die NuweTestamentiese tekste die vreemde gestalte van die Heer in die werklikheid probeer verstaan. Sy benadering kom neer op 'n Christelik-kritiese na-kritese ingesteldheid (vgl Van der Merwe 1987:202-203).

Die vraag is egter wat presies Schoeman in gedagte het. As hy meen dat die mitiese kruike waarin die evangelie gegiet is, nie gebreek moet word nie, is hy dit eintlik met Bultmann eens, aangesien Bultmann duidelik stel dat ontmitologisering nie eliminering beteken nie, maar interpretasie van die mite (Bultmann 1967:21-22). Die vraag na hoe die skat uit die kruik gehaal moet word, word nie so duidelik beantwoord nie. Bultmann se kritiek op diegene wat meen dat die taal van geloof noodwendig mitologiese taal moet wees, is hier van toepassing, naamlik dat juis hulle van die mitologiese wil 
ontsnap deur die mitologiese as noodsaaklike beelde en simbole voor te stel (Bultmann 1965:185-186). Myns insiens is dit presies wat by Schoeman gebeur. Is sy navolging van Jung nie sprekend hiervan nie? Net so is dit ook nie duidelik hoe die vreemde gestalte van die Heer in die werklikheid vanuit die Nuwe-Testamentiese tekste deur hom verstaan sal word nie. Die probleem dat moderne mense met 'n wetenskaplike wêreldbeeld die mitologiese spreekwyse van die Nuwe-Testamentiese tekste moeilik verstaanbaar mag vind, of daar nou by hulle ruimte vir mitologie sou wees of nie, word nie deur Schoeman aangespreek nie. Dit lyk eerder asof hy die probleem onkrities probeer systap met 'n sosiale pypkanbeweging en deur sy stem te voeg by die koor van Bultmann-kritici.

Die vergelyking van die kennissosiologiese resultate met Bultmann s'n het neergekom op ' $n$ bevestiging van die geldigheid van Bultmann se ontmitologiseringsprogram (Malan \& Van Aarde 1998:529-543). Myns insiens het ons juis in hierdie opsig 'n belangrike vraag om te beantwoord. Dit is naamlik of die kennissosiologie nie op 'n eiesoortige manier ontmitologiserend te werk gaan nie, sonder om dit doelbewus te doen of so te noem. Ek meen dat hierdie vraag wel positief beantwoord kan word, ten spyte daarvan dat die kennissosiologiese benadering in wese fenomenologies-beskrywend is. Die kennissosiologiese benadering maak gebruik van die simboliese en sosiale universums by die bestudering van antieke tekste in 'n poging om die tekste vir mense in die hede verstaanbaar te maak. Dat die begrippe wêreldbeeld en simboliese universum grootliks oorvleuel, is reeds gestel (Malan \& Van Aarde 1998). Dit beteken dat, soos Bultmann, hierdie benadering van die veronderstelling uitgaan dat daar 'n verskil is tussen die antieke wêreldbeeld en die moderne een. Daarmee saam gaan 'n tweede veronderstelling, naamlik dat die teks alleen verstaanbaar vir moderne mense sal wees, indien hierdie verskil in wêreldbeeld erken word. So gesien, word 'n baie belangrike aspek, naamlik die hermeneutiese gerigtheid van die kennissosiologiese benadering, myns insiens duideliker. $\mathrm{Na}$ aanleiding van die oorvleueling van die resultate met dié van Bultmann se benadering wat hermeneuties gerig is, kan ek nie anders as om te aanvaar dat die kennissosiologiese benadering nie uitsluitlik fenomenologies-beskrywend van aard is nie.

Daarmee saam is die vraag of enige interpretasie van die Nuwe-Testamentiese tekste wat rekening hou met die historiese kloof tussen die moderne leser en die antieke 
teks, nie soms kan neerkom op 'n soort ontmitologiserende interpretasie nie. Selfs Hans Jonas wat die mitologiese metaforiese taal van die Nuwe Testament telkens weer in nuwe metafore wil vertaal, en Schoeman wat die mitologie sosiaal wil aanwend, moet uiteindelik een of ander vorm van 'n moderne interpretasie van die mitologiese taal van die Nuwe Testament weergee. Dit beteken dat die probleem van die mitologiese taal en wêreldbeeld van die Nuwe Testament of aanvaar, of gesystap, of ontmitologiserend geïnterpreteer moet word. In die laaste geval kan ontmitologisering programmaties en doelbewus gedoen word, soos Bultmann dit gedoen het. Aan die ander kant kan ontmitologisering ook as deel van die historiese benadering byna onbewustelik en onbedoeld gebeur soos met die toepassing van die kennissosiologiese model.

\section{BULTMANN SE DEFINIËRING VAN DIE MITE}

Daar was uit verskeie oorde kritiek op Bultmann se definiëring van die mite. Klaus Bockmuehl (1988:22, 30-31) sien 'n ooreenkoms tussen Bultmann en Feuerbach se definiëring van die mite. Vir albei is die mite volgens hom uitdrukking in kosmologiese terme van die mens se verstaan van eksistensie. Volgens hom is die program van optrede by albei ook dieselfde: die Nuwe-Testamentiese inhoude word geïnterpreteer deur die historiese van die mitologiese te skei en alle godsdienstige uitsprake word as mitologiese uitsprake beskou. Having banished the historical element, they can then criticise or interpret the "meaning" (Bockmuehl 1988:30). Vir Bockmuehl beteken ontmitologisering niks anders nie as ' $n$ allegorisering van die Nuwe-Testamentiese kerugma en is die uiteinde daarvan ateïsme. Terwyl Feuerbach dit volgens hom openlik erken, meen hy daar is by Bultmann 'n poging om ateïsme te vermy. Hy sien egter die verdere verloop van Bultmann se denke by van sy navolgers soos Herbert Braun as 'n ontwikkeling na ateïsme (Bockmuehl 1988:31-43).

Die belangrikste oorsaak van al die kritiek op Bultmann se definiëring van die mite is waarskynlik dat die historiese oorsprong daarvan nie altyd reg verstaan is nie. Bultmann het dit wel gestel dat sy definièring van die mite ooreenstem met die Religiongeschichtliche Schule se verstaan van die saak: Mythos ist der Bericht von einem Geschehen oder Ereignis, in dem übernatürliche, übermenschliche Kräfte oder Personen 
wirksam sind (daher oft einfach als Göttergeschichte definiert). Mythisches Denken ist der Gegenbegriff zum Wissenschaftlichen Denken (Bultmann 1965:180).

Wanneer daar egter gekyk word na hoe die Religiongeschichtliche Schule met die begrip mite omgaan, is die saak nie so eenvoudig nie. 'n Mens sou inderdaad uit Bultmann se uitspraak die afleiding kon mak dat hy in hierdie opsig sou aansluit by Bousset en Gunkel, maar Schmithals (1995:171-178) toon met oortuiging aan dat dit nie sonder meer die geval is nie. Hy wys in 'n historiese ondersoek na die gebruik van die Religionsgeschichtliche Schule se aanwending van die begrip mite op 'n belangrike aspek. Die is naamlik dat die Religionsgeschichtler self dit angstig vermy het om hulle begrip van die mite op die Nuwe Testament toe te pas. Hy verwys onder andere na 'n uitspraak van Gunkel in die RGG: .... vom Mythos im Neuen Testament ist keine Rede, en na Johannes Weiss se gevolgtrekking met betrekking tot die Christologiese titel Seun van God, dat die mitiese denke .... völlig abgetötet [ist]. Ook Bousset en Wrede vermy die begrip mite in hulle uitsprake oor die Nuwe Testament. Om die afleiding te maak dat Bultmann sy toepassing van die religionsgeschichtliche begrip van die mite net so oorgeneem het van sy leermeesters, is 'n oorvereenvoudiging. Hoewel Bultmann dieselfde definisie as hulle gebruik het, moes die verstaan daarvan verskil het aangesien hulle nie soos Bultmann mites in die Nuwe Testament gevind het nie. Dit is volgens Schmithals onseker of Bultmann van Ernst Troeltsch se aanwending van die begrip mite kennis geneem het. Hoewel Troeltsch hom nie op die problematiek rondom die mite toegespits het nie, is daar 'n opvallende ooreenstemming tussen die twee, naamlik die aanvaarding dat die sentrale figuur van die Christelike mitologiese spreke ' $n$ historiese persoon is.

Schmithals is egter daarvan oortuig dat Fritz Gogarten se aanwending van die begrip mite 'n sterk invloed op Bultmann uitgeoefen het: .... ist Gogartens 1917 erschienene Schrift "Religion weither", deren Bedeutung für Bultmann nicht überschätzt werden kann, ein leidenschaftliches Plädoyer für den Mythos (Schmithals 1995:176). Hy onderstreep die feit dat Bultmann groot waardering gehad het vir hierdie werk van Gogarten en dit as 'n wundervollen Buchlein bestempel het (Schmithals 1995:177). Alhoewel die Religionsgeschichtler buiten Gogarten nie die begrip mite op die Nuwe Testament toegepas het nie, en selfs gemeen het dat dit nie in die Nuwe Testament 
voorkom nie, verskil Gogarten en Bultmann se toepassing van die begrip op die Nuwe Testament volgens hom nie daarvan nie.

Vanuit die latere godsdienswetenskap is daar 'n andersoortige benadering tot die mite. Waar Bultmann gestel het dat die mite 'n voorstelling is van die nie-wêreldlike en goddelike van die anderkant (Jenseits) as wêreldlik en menslik van die duskant (Diesseits), word die mite presies andersom gesien. Schoeman (1981:12) dui aan dat die mite deur godsdienswetenskaplikes soos Otto, Eliade en Kerenji beskou word as mense se poging om hulleself na die anderkant toe te projekteer. Daarby wys hy daarop dat daar by die godsdienswetenskaplikes 'n onderskeid gemaak word tussen mitiese stof en mitiese ingesteldheid. Dit beteken dat die mens sonder om met mitiese stof as sulks besig te wees, steeds ' $n$ mitiese ingesteldheid kan hê en so mities besig kan wees. Hy meen, in navolging van Jung en Eliade, dat die mite nog in die bewussyn van die mens voortleef en die diepste emosionele behoefte van die mens verteenwoordig, naamlik om die tyd te transendeer.

Grässer (1994: 274-275) meen egter dat alhoewel daar vandag nie meer met Bultmann se religionsgeschichtliche definisie van die mite volstaan kan word nie, dit beslis ook nie net opsy geskuif kan word sonder om daarop ag te slaan nie, omdat hy die belangrike onderskeid tref tussen die geslote wetenskaplike wêreldbeeld en die mitologiese wêreldbeeld wat oop is. Die feit bly egter staan dat Bultmann (1965:179) daarmee vrede gehad het as iemand onder die begrip mite iets anders as hy verstaan het.

\section{HERWAARDERING}

Om aan die uitdrukking van outentieke eksistensie wat die antieke tekste van die Nuwe Testament bevat, reg te laat geskied, moet die mitologiese taal en wêreldbeeld waarin daardie Existenzverständniss gegiet is, vir moderne mense verstaanbaar gemaak word. Blote wegsny van die mitologiese taal sou 'n radikale verskraling van die Existenzverständniss van die tekste meebring. Bultmann se program van ontmitologisering bied myns insiens 'n verantwoordelike asook 'n verantwoorde poging om aan die saak reg te laat geskied. 


\section{Literatuurverwysings}

Bockmuehl, K 1988. The unreal God of modern theology: Barth, Bultmann and the theology of atheism: A call to recovering the truth of God's reality. Colorado Springs: Helmers \& Howard.

R K Bultmann [1933] 1958. Glauben und Verstehen: Gesammelte Aufsätze, I. 3. Aufl. Tübingen: Mohr.

- 1960. Die Christliche Hoffnung und das Problem der Entmythologisierung, in Bultmann 1958:81-90.

-1965. Zum Problem der Entmythologisierung, in Bartsch, H-W (Hrsg), Kerygma und Mythos, II: Diskussionen und Stimmen zum Problem der Entmythologisierung, 179-195. Hamburg-Bergstedt: Herbert Reich Evangelischer Verlag. (ThF2.)

- 1967. Neues Testament und Mythologie: Das Problem der Entmythologisierung der neutestamentlichen Verkündigung, in Bartsch, H-W(Hrsg), Kerygma und Mythos, I: Ein theologisches Gespräch, 15-48. Hamburg-Bergstedt: Herbert Reich Evangelischer Verlag. (ThF1.)

De Silva, D A 1992. The meaning of the New Testament and the skandalon of world constructions. EvQ 64(1), 3-21.

Grässer, E 1994. Notwendigkeit und Möglichkeiten heutiger Bultmanninterpretation. ZThK 91(3), 272-284.

Jonas, H 1982. Is faith still possible? Memories of Rudolf Bultmann and reflections on the philosophical aspects of his work. HThR 75(1), 1-23.

Loubser, J A 1996. Aspekte van Bultmann se Pauliniese teologie. NGTT 37(1), 49-60.

Luz, U 1966. Entmythologisierung als Aufgabe der Christologie. EvTh 26, 349-368.

Malan, G \& Van Aarde, A G 1988. 'n Kennissosiologiese benadering tot die dag van die Here in 2 Petrus. HTS 54(3\&4), 529-543.

Pelser, G M M 1987. Die ontmitologiseringsprogram van Rudolf Bultmann. HTS 43, 162-191.

Perrin, N 1979. The promise of Bultmann. Philadelphia: Fortress.

Schelkle, K H 1985. Entmythologisierung in existentialer Interpretation. ThQS 165(4), 257-266.

Schmithals, W 1966. Die Theologie Rudolf Bultmanns: Ein Einfürung. Tubingen: Mohr. 
Schmithals, W 1995. Zum Problem der Entmythologisierung bei Rudolf Bultmann. ZThK 92(2) 166-206.

Schoeman, P 1981. Mitologie en godsdiens. ThEv(SA) 14(1), 10-22.

Van der Merwe, P J 1987. Die wonder en wondervertelling gesien teen die agtergrond van mite en ontmitologisering. HTS 43, 192-204. 